\section{Effect of presentation procedure on taste intensity functions*}

\author{
HERBERT L. MEISELMAN \\ U.S. Army Natick Laboratories, Natick, Massachusetts 01760
}

Magnitude estimations were made for the taste intensity of sodium chloride $(\mathrm{NaCl})$ and quinine sulfate $\left(\mathrm{QSO}_{4}\right)$ presented by three different methods: sip, anterior dorsal tongue flow, and whole-mouth flow. Power functions fitted to the data indicate that, for the anterior tongue stimulus $(\mathrm{NaCl})$, the two flowing procedures produced lower exponents than did the sip procedure. For the posterior tongue stimulus $\left(\mathrm{QSO}_{4}\right)$, the exponent obtained with dorsal tongue flow was lower than the exponents obtained with either of the whole-mouth procedures, sip or flow. The results are compared to previous experiments on ratio scaling of taste intensity to elucidate the effects of several procedural variables.

Many gustatory psychophysical experiments with human Ss still use the traditional sip technique: a solution is presented in a small beaker, whose contents $(5-10 \mathrm{ml}$ in most experiments) are poured into the mouth, sampled, and expectorated (see Meiselman, 1968; Stevens, 1969). The sip technique has the advantage of using the normal human mode of taste stimulus ingestion, and of permitting the salivary environment and tongue movements characteristic of the $\mathrm{S}$. It requires maximally simple equipment and minimal control of stimulus delivery by the $E$. The $S$ may pour the solution quickly or slowly, take all of it or only a part, or take repeated small sips rather than one continuous presentation. Appropriate instructions can help to overcome some of these potential sources of variability.

Two other procedures use a continuously flowing stimulus. The most widely used is called dorsal tongue flow: a continuous flow of solution is aimed at the anterior dorsal surface of the tongue, which is extended from the mouth with the lips closed over it in order to seal off the remainder of the tongue from the mouth chamber and its saliva. McBurney (1966), Bartoshuk (1968), and others have used dorsal tongue flow in a variety of testing situations in order to investigate the effects of both adaptation and presentation of single brief stimuli. The advantages of the dorsal tongue flow are stimulus constancy and the absence of most of the saliva, although contributions from the glands of the tongue itself (Bloom

*This research was conducted at Cornell University during the author's tenure as a postdoctoral research fellow of the United States Public Health Service (5-F02-MH-34451). Dr. Bruce Halpern is thanked for his gracious provision of space, equipment, and personnel, and for his helpful advice throughout the research. Mr. George Batik, Biological Illustrator at Cornell University, provided the drawing for Fig. 1.
\& Fawcett, 1962) cannot be eliminated. The main drawback of the dorsal flow is the disuse of much of the tongue and mouth cavity. Because areas of the mouth are differentially sensitive to different chemical stimuli (Henkin \& Christiansen, 1967; Marcström, 1967), elimination of particular areas of the mouth and tongue may differentially affect responses to various stimulus solutions.

In the 1930s the Cornell gustometer was introduced; this permits the $\mathbf{E}$ to siphon solutions through the closed, whole mouth (Krakauer \& Dallenbach, 1937; Abrahams, Krakauer, \& Dallenbach, 1937; Dallenbach \& Dallenbach, 1943). A dam was constructed using dental impression compound into which an inflow and an outflow tube were imbedded. Closing the teeth onto the impression compound provided a closed, whole-mouth flow system. The solution was introduced into the tongue by a tube and flowed by gravity to a collecting point just behind the lower front teeth, where it was removed by the siphoning action of the outflow tube. Using whole-mouth flow, Krakauer \& Dallenbach (1937) and Abrahams, Krakauer, \& Dallenbach (1937) found relatively rapid adaptation times for sodium chloride $(\mathrm{NaCl})$, quinine sulfate $\left(\mathrm{QSO}_{4}\right)$, tartaric acid, and sucrose. As with dorsal tongue flow, whole-mouth flow maintains stimulus constancy, but has the advantage of utilizing the entire mouth. Saliva mixes with the stimulus but is presumably drawn off as fast as it enters the stimulated area. Both anterior dorsal flow and whole-mouth flow present stimuli simultaneously to all parts of the receptor surface. This presumably occurs only rarely during normal eating or drinking.

Psychophysical research on taste magnitude has yielded some widely divergent results. Although ratio scaling of taste intensity has routinely yielded power functions for a number of taste stimuli, wide discrepancies have been reported in the exponents of the functions. For example, the published exponents for $\mathrm{NaCl}$, the classical salty stimulus, have varied from 1.59 (Ekman, 1961) to 0.41 (McBurney, 1966); for $\mathrm{QSO}_{4}$, a bitter stimulus, from 1.0 (Stevens, 1969; Moskowitz, 1968) to 0.30 (Smith, 1969); for sucrose, the sweet stimulus, from 1.8 (Meiselman \& Halpern, 1970) to 0.46 (Feallock, 1965); and for citric acid, a sour stimulus, from 0.75 (Kocher \& Fisher, ${ }^{1}$ 1969) to 0.46 (Smith, 1969). The discrepancies suggest that if factors responsible for divergent exponents to the same stimulus source could be identified, the several psychophysical methods and the aspects of gustation that they measure would be better understood.

Two independent variables in the psychophysics of taste are the procedure for stimulus presentation and the level of adaptation. An experiment was undertaken to investigate the effects of both these variables on taste intensity functions. The present paper reports the effects of presentation procedure only. The three procedures described above were used to present five concentrations of two stimulus compounds. Both an anterior tongue stimulus $(\mathrm{NaCl})$ and a posterior tongue stimulus $\left(\mathrm{QSO}_{4}\right)$ were used to accentuate possible differences among the procedures relative to gross tongue localization.

\section{Subjects}

\section{METHOD}

The Ss were six nonsmoking male undergraduate students at Cornell University, between 18 and 21 years of age. They were chosen from a larger group on the basis of their performance on a gustatory screening task previously described by Meiselman \& Dzendolet (1967, Experiment 2). Each S had reliably assigned the appropriate quality labels in at least six out of seven presentations of the screening stimuli. All the Ss had had previous experience with gustatory research, using both sip and dorsal tongue flow presentations, and with magnitude estimation. The Ss did not know the purpose of the research and were paid for their participation in the experiment.

\section{Stimuli}

All solutions were prepared with distilled water (conductivity $<6 \times 10^{-6} \mathrm{mhos} / \mathrm{cm}$, refractive index $=1.3330$ ) and either reagent grade $\mathrm{NaCl}$ or U.S.P. grade $\mathrm{QSO}_{4}$. On the basis of an earlier experiment (Meiselman, 1968) with different $S s$, a series of five concentrations of each stimulus was 


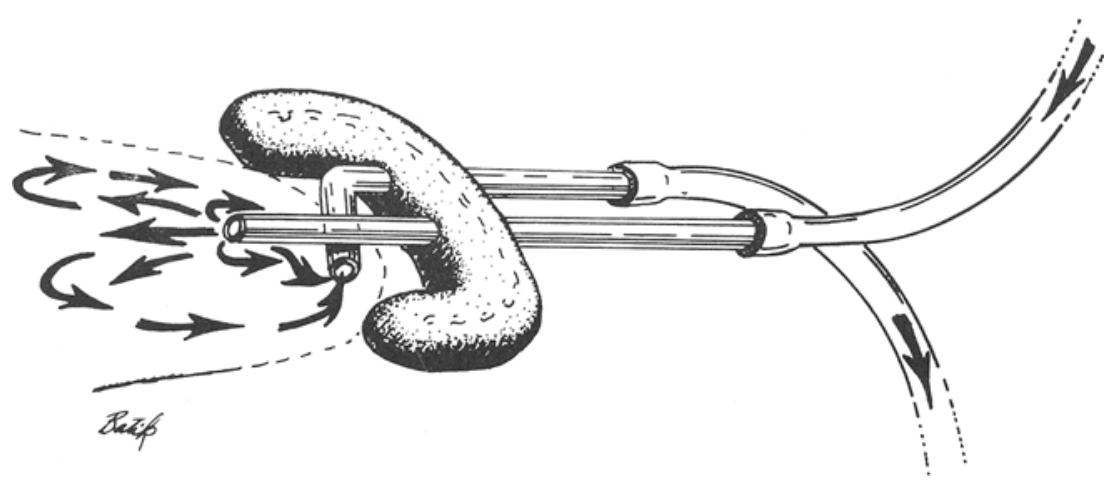

Fig. 1. Gustatory whole-mouth stimulator. Solution is introduced onto the tongue, from which it naturally drains to a point behind the lower front teeth and is siphoned out of the mouth cavity. The stimulator is held firmly by a dental impression compound bite-bar, and the tubes in contact with the mouth are annealed glass.

chosen to match the average magnitude estimations for each concentration between the two chemical stimuli. The concentrations of $\mathrm{NaCl}$ were $180,255,360,510$, and $720 \mathrm{mM}$; and of $\mathrm{QSO}_{4}, 0.0375,0.076$, $0.155, \quad 0.315,0.600 \mathrm{mM}$. Solutions were placed in a water bath and presented to the Ss at $32^{\circ} \mathrm{C}$.

\section{Presentation Procedures}

The stimulus solutions were presented with three different methods. In the sip procedure, $10 \mathrm{ml}$ of solution were presented in a plastic cup, with the instructions that the $S$ pour all of the solution into his mouth. The plastic cup was discarded after each stimulus presentation. With dorsal tongue flow, the $S$ extended his tongue between his lips and closed his lips on his tongue. A flow of solution was directed onto the exposed anterior dorsal tongue surface. The apparatus for whole-mouth flow was similar to the Cornell gustometer and permitted delivery of a flow of solution to the whole mouth cavity (Fig. 1). With both the sip procedure and the whole-mouth flow procedure, the $S$ was asked to move his tongue gently.

\section{Procedure}

The S sat comfortably in front of a solution delivery tube and a funnel that collected expectorations and stimulus outflow. For presentation with the sip procedure, solutions from the delivery tube were directed into small plastic cups. For dorsal flow, the $S$ extended his tongue into the flow of solution, and for whole-mouth flow, the mouthpiece was connected to the delivery tube. Solution flowed from the outflow tube at approximately $5 \mathrm{ml} / \mathrm{sec}$. On a wall next to the delivery tube and collection funnel was a clipboard with data sheets on which the $S$ could record his own data. The data sheet was removed after each stimulus presentation.
(0.31), whereas the exponent for whole-mouth flow $(0.52)$ is similar to the sip exponent $(0.54)$.

On the basis of these data, the mode of stimulus presentation appears to exert a sizable effect on the function relating taste intensity and stimulus concentration. This effect varies for stimuli that differentially affect separate gross tongue areas. Thus, inclusion of the posterior tongue has a negligible effect on the exponent for $\mathrm{NaCl}$ whether either the stimulus is continuously renewed and flowing or it is not replaced and interacting with the saliva. The function for anterior dorsal tongue is more similar to the whole-mouth function than to the sip function, although the latter two stimulate the entire mouth, whereas the dorsal flow does not. The sip function, which yields small magnitude estimates at low concentrations and then rapidly increases at high concentrations to large estimates, which exceed those of the other two presentation methods, may reflect the effect of salivary environment. The low concentrations would be competing for gustatory receptor sites already partially filled with the similar concentration of salivary $\mathrm{NaCl}$. Thus, the function would rise very slowly at first and more rapidly later, yielding a greater slope. The smaller estimates for the higher concentrations when presented

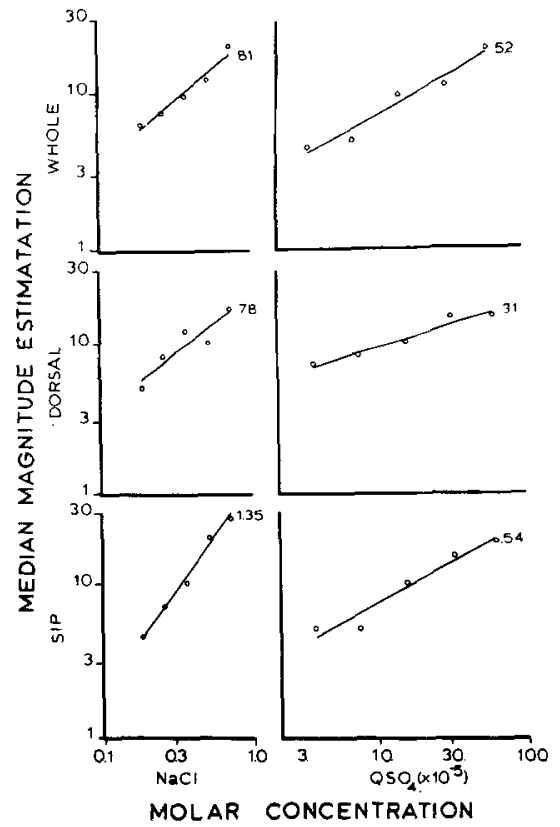

Fig. 2. Median magnitude estimations as a function of molar concentration plotted on log-log coordinates. Each point represents 12 measurements, two replications on each of six Ss. Power functions have been fitted to the data, and the slopes of the best-fitting straight lines are shown next to each function. 
with the flow procedure suggest that flow procedures may increase removal of stimulus from $\mathrm{NaCl}$ receptors, or may move the stimulus over the surface of the tongue so rapidly that it does not penetrate the tongue folds. The effect of either of these would be to limit maximum response magnitude. An experiment that independently varied flow rate might help to decide whether or not flow rate is related to these observations of lowered response to higher concentrations.

For the posterior tongue stimulus $\mathrm{QSO}_{4}$, the effect of an unreplaced vs a flowing stimulus presentation has a negligible effect, since two procedures that stimulate the entire mouth have almost identical exponents. The dorsal tongue presentation yielded an exponent much lower than the other two procedures, suggesting that gross tongue localization is a more important determinant of exponent than stimulus mobility for the posterior tongue stimulus. The absence of a competing salivary component for $\mathrm{QSO}_{4}$ is consistent with the lack of a difference between sip and whole-mouth flow.

Table 1 presents these data, with previously reported taste function exponents. For each stimulus compound, the exponents are listed in order of decreasing size, with the procedure used in the study indicated by the column in which the reference is listed. Experiments cited on the left of the exponents used a sip procedure, and experiments cited on the right used flowing procedures. The mode of flow is indicated by the letter following the reference. In a further breakdown, the exponents for the two sweet stimuli, sucrose and saccharin, are identified as to whether the $S$ was instructed to estimate total ( $t$ ) taste intensity or sweet (s) intensity only.

With few exceptions, the exponents generated by an experiment that used sipping are higher than those generated by experiments that used flowing, irrespective of the mode of flow. For both $\mathrm{NaCl}$ and quinine, the exponents calculated for whole-mouth flow in the present experiment are the highest or second highest exponents for any experiment using a flowing stimulus. The size of the anterior dorsal tongue area stimulated has been shown to have no systematic effect on exponents for $\mathrm{NaCl}$, citric acid, $\mathrm{QHCl}$, and saccharin when area was varied between 4 and $126 \mathrm{~mm}^{2}$ (Smith, 1969). Feallock (1966) also used a moderately small stimulating area, $1 \mathrm{~cm}$ in diam, and obtained exponents similar to those of other Es who presented a flowing stimulus to larger anterior dorsal tongue areas. Area differences can, therefore, be

Table 1

Exponents for Previously Reported Taste Functions. Exponents are listed in order of decreasing size. Experiments cited to the left of the exponent used a sip procedure, and those cited to the right used a flow procedure. The flowing experiments are distinguished as follows: $D$, dorsal flow; $W$, whole mouth flow; d, dorsal flow to a small area. For the sweet stimuli, instructions were to estimate sweet intensity (s) only or total taste intensity ( $t$ ). The present experiment is cited as Meiselman (1970).

Sip

\section{Ekman, 1961}

Ekman \& Akesson, 1965

Meiselman, 1968

Moskowitz, 1968

Stevens, 1969

Meiselman, 1970

Stevens, 1960

Jones \& Marcus, 1961

Lewis, 1948

Borg et al, 1967

Bruvold \& Gaffey, 1965

\section{Sodium Chloride}

1.59

1.58

1.43

1.4

1.4

1.35

1.3

1.05

1.00

1.00

0.92

0.80 Meiselman, $1970(\mathrm{~W})$

0.78

0.54

0.49

0.44

0.42

0.41

Stevens, 1969

Moskowitz, 1968

Meiselman, 1968

Ernits, 1967 (Unpublished)

Meiselman, 1970

Quinine (Hydrochloride and Sulfate)

1.0

1.0

0.98

0.86

0.54

Meiselman, 1970 (D)

Kocher \& Fisher, 1969 (D)

Smith, 1969 (D)

Feallock, 1965 (d)

Bartoshuk, 1968 (D)

McBurney, 1966 (D)
Moskowitz \& Arabie, 1971

0.54

0.52

0.49

0.49

0.36

0.32

0.31

0.30

Sucrose

1.80

Meiselman \& Halpern, 1970 (s)

Moskowitz, 1970 (s)

Ekman \& Ȧkesson, 1965 (s)

Moskowitz, 1968 (s)

Moskowitz, 1970 (t)

Stevens, 1960 (t)

Stevens, 1969 (s)

Stone \& Oliver, 1969 (s)

Meiselman \& Halpern, 1970 ( $t$ )

Meiselman, 1968 (t)

1.60

1.47

$$
1.4
$$

1.4

1.3

\section{3}

0.98

0.98
0.79

0.70

0.67

0.62

0.46

Gregson \& Russell, 1965 (t)

Stevens, $1960(t)$

Stevens, $1969(\mathrm{t})$

Moskowitz, 1970 (t)

Moskowitz, 1970 (s)

Saccharin

0.8

0.8

0.6

0.3

0.16

Hydrochloric Acid

1.48

Meiselman, 1968

0.87

0.84

Citric Acid

0.75

Moskowitz, 1971

0.72

0.67

0.46

Ernits, 1967 (D)

Meiselman, 1970 (W)

Kocher \& Fisher, 1970 (D)

Feallock, 1965 (d)

Bartoshuk, 1968 (D)

Meiselman, 1970 (D)

Smith, 1969 (D)

Kocher \& Fisher, 1969 (D)

Bartoshuk, 1968

Feallock, 1965 (d)

(d)

Borg et al, 1967

eliminated as a source of difference between whole mouth and anterior dorsal tongue.

Although the exponent for whole-mouth flow of $\mathrm{NaCl}$ in the present study is the largest reported, it is almost identical to that for dorsal flow, and both are higher than others 
previously reported for flowing stimuli. These higher values are probably due to the narrow ranges of $\mathrm{NaCl}$ and $\mathrm{QSO}_{4}$ used in the present study (Poulton, 1968). Although there is a negligible difference in the present experiment between the two exponents for flowing $\mathrm{NaCl}$, the exponent for anterior dorsal flow of $\mathrm{QSO}_{4}$ is much lower than for whole-mouth flow. Thus, there is little evidence for a difference in exponent between whole-mouth flow and dorsal flow of an anterior tongue stimulus. The conclusion for the posterior tongue stimulus is not as clear, although dorsal flow possibly yields a lower exponent than whole-mouth flow.

Most of the discrepancies between the reported exponents for sucrose can be accounted for by considering whether $S$ was asked to rate total intensity or sweetness. For sucrose, the difference is possibly traceable to the contribution of bitterness to the total taste at low concentrations (Meiselman \& Halpern, 1970). Adding bitterness to the sweetness to arrive at total intensity raises the lower end of the function of total taste intensity and decreases the slope.

What are possible explanations of the observed differences between the sipping and flowing procedures? It is doubtful that the different presentation procedures actually present different effective stimulus concentrations to the tongue, and the $S$ is reporting the taste intensity appropriate to the different levels of stimulation. Such a mechanism could not easily account for the change in slope of the taste function with change in procedure, for it would necessitate that the proportion of a stimulus that was effective changed at each level of concentration.

A possible source of confusion lies in separating experiments into those that present the stimulus by sipping and those that present it by flowing. The lowest four $\mathrm{NaCl}$ exponents (0.49-0.41) were obtained by presenting a flowing stimulus immediately preceded by a distilled water rinse. However, the present experiment obtained differences in exponents between sipped and flowed $\mathrm{NaCl}$ with a prerinse, and Kocher \& Fisher (1969) obtained relatively low exponents for $\mathrm{NaCl}$ without a prerinse. Stevens (1969) reported that rinsing between sipped stimuli had no effect on the taste function for $\mathrm{NaCl}$, and this lack of effect might be generalizable to the prerinses used immediately preceding a stimulus.

Naturally, an extended rinse immediately preceding stimulus presentation would sharply reduce the amount of salivary $\mathrm{NaCl}$ available to the gustatory receptor sites. This should have the effect of increasing the magnitude estimates given to low concentrations of the stimulus. This should shift up the lower end of such functions, resulting in flatter functions with generally lower slopes. A prerinse would not similarly affect $\mathrm{QSO}_{4}$ because it is not part of the salivary e $n$ i ron m e t, although cross-adaptation between salivary constituents and weak stimuli is another possibility.

Thus neither argument, effective concentration or rinsing, can explain the differences between sipping and flowing presentation of taste stimuli. Further studies are needed to determine why the percept of a flowing stimulus should be different from that of a sipped stimulus. Comparisons among psychophysical studies of taste should take these observations into account.

\section{REFERENCES}

ABRAHAMS, H., KRAKAUER, D., \& DALLENBACH, K. Gustatory adaptation to salt. American Journal of Psychology, $1937,49,462-469$

BARTOSHUK, L. M. Water taste in man. Perception \& Psychophysics, 1968, 3, 69-72.

BLOOM, W. \& FAWCETT, D. W. $A$ textbook of histology. Philadelphia: Saunders, 1962.

BORG, G., DIAMANT, H., STROM, L., \& ZOTTERMAN, Y. The relation between neural and perceptual intensity: $A$ comparative study on the neural and psychophysical response to taste stimuli. Journal of Physiology, 1967, 192, 13-20.

BRUVOLD, W. H., \& GAFFEY, W. R Subjective intensity of mineral taste in water. Journal of Experimental Psychology, 1965, 69, 369-374.

DALLENBACH, J. W., \& DALLENBACH, K. M. The effects of bitter adaptation on senstivity to the other taste qualities. American Journal of Psychology, 1943, $56,21-31$.

EKMAN, G. Methodological note on scales of gustatory intensity. Scandinavian Journal of Psychology, 1961, 2, 185-190.

EKMAN, G, \& ÁKESSON, C. Saltiness, sweetness and preference: A study of quantitative relations in individual subjects. Scandinavian Journal of Psychology, 1965, 6, 241-253.

ERNITS, T. Magnitude estimation of quinine sulfate with two methods of stimulus presentation. Unpublished undergraduate research project, Brown University, 1967.

FEALLOCK, J. B. Estimated magnitudes of taste under improved conditions of stimulus control. Unpublished doctoral thesis, University of Virginia, 1966.

GREGSON, R. A. M., \& RUSSELL, P. N. Psychophysical power law exponent value for sucrose intensity. Perceptual \& Motor Skills, 1965, 20, 294.
HENKIN, R. I., \& CHRISTIANSEN, R. L. Taste localization on the tongue, palate and pharynx of normal man. Journal of Applied Physiology, 1967, 22, 316-320.

JONES, F. N., \& MARCUS, M. J. The subject effect in judgments of subjective magnitude. Journal of Experimental Psychology, 1961, 61, 40-44.

KOCHER, E. C., \& FISHER, G. L Subjective intensity and taste preference. Perceptual \& Motor Skills, 1969, 28, 735-740.

KRAKAUER, D., \& DALLENBACH, K. M. Gustatory adaptation to sweet, sour, and bitter. American Journal of Psychology. $1937,49,469-475$.

LEWIS, D. R. Psychological scales of taste. Journal of Psychology, 1948, 26, 437-446.

MARCSTRöM, A. Studies on the connection between physiochemical properties and stimulating abilities of some sweet and bitter compounds. Axkiv för Zoologi, 1967, 19, 421-535.

MCBURNEY, D. H. Magnitude estimation of the taste of sodium chloride after adaptation to sodium chloride, Journal of Experimental Psychology, 1966, 72, 869-873.

MEISELMAN, H. L. Adaptation and cross-adaptation of the four gustatory qualities. Perception \& Psychophysics, $1968,4,368-372$.

MEISELMAN, H. L., \& DZENDOLET, E. Variability in gustatory quality identification. Perception \& Psychophysics, 1967, 2, 496-498.

MEISELMAN, H. L., \& HALPERN, B. P. Effects of Gymnema sylvestre on complex tastes elicited by amino acids and sucrose. Physiology \& Behavior, $1970,5,1379-1389$.

MOSKOWITZ, H. R. Scales of intensity for single and compound tastes. Unpublished doctoral thesis, Harvard University, 1968.

MOSKOWITZ, H. R. Sweetness and intensity of artificial sweeteners. Perception \& Psychophysics, 1970,8, 40-42.

MOSKOWITZ, H. R. Ratio scales of acid sourness. Perception \& Psychophysics, $1971,9,371-374$.

MOSKO'WITZ, H. R., \& ARABIE, P. Texture intensity as a function of stimulus for concentration and solvent viscosity. Joumal of Texture Studies, 1970, 1, 502-510.

POULTON, E. C. The new psychophysics: Six models for magnitude estimation. Psychological Bulletin, 1968, 69, 1-19.

SMITH, D. The effect of area of stimulation on the intensity of human gustatory responses. Unpublished doctoral thesis, University of Pittsburgh, 1969.

STEVENS, $S, S$. Psychophysies of sensory function, American Scientist, 1960, 48, 226-253.

STEVENS, S, S. Sensory scales of taste intensity. Perception \& Psychophysics, $1969,6,302-308$

STONE, H., \& OLIVER, S. Measurement of the relative sweetness of selected sweeteners and sweetener mixtures. Journal of Food Sciences, 1969, 34, 215-222.

\section{NOTE}

1. Throughout this paper, the results reported for Kocher \& Fisher (1969) are the averages of Ss JM, GF, and RP. The other Ss were eliminated because of extremely flat functions for all stimuli.

(Accepted for publication December 12 1970.) 